\title{
Artificial Intelligence Based Training and Placement Management
}

\author{
Krishanu Deb, Pankaj Agrawal, Harish Nawale, Shradha Jadhav, Prof. Manisha Darak \\ Department of Computer Engineering, Siddhant College of Engineering, Pune, Maharashtra, India
}

\begin{abstract}
Training and placement cell in colleges is to carry out all the job interviews and skill development procedures of the candidates, all this procedures are carried out either manually or some sort of database software which is slow and sloppy, We hereby took a step forward to build an Artificial Intelligence based solution to the problem, we propose a system where admin and student can carry out all the training and placement related operations with the implementation of an Artificial Intelligence based environment where user can communicate with artificial intelligence based control system.
\end{abstract}

Key Words: Artificial Intelligence, Natural Language Processing, Chatbot, Articial Intelligence Markup Language

\section{INTRODUCTION}

Training and Placement Cell is to guide students to choose right career and to give knowledge, skill, and aptitude and meet the man power requirements of the industry, to assist students to develop/clarify their academic and career interests, and their short and long-term goals through individual counseling and group sessions maintaining and regularly updating the database of students, maintaining database of companies and establishing strategic links for campus recruitments, gathering information about job fairs and all relevant recruitment advertisements, coordinating with companies to learn about their requirements and recruitment procedures, identifying the needs and expectations of the companies to assist them in recruiting most suitable candidates, organizing pre-placement training/workshops/ seminars for students, arranging periodic meetings with Human Resources Department of companies and Training and Placement Officer's to promote recruitments, assist students for industrial training at the end of the fourth and sixth semester, provide resources and activities to facilitate the career planning process, act as a link between students, alumni, and the employment community, to assist students in obtaining placement in reputed companies. Keeping in view the industry requirements, the training curriculum is designed for preparing the students for entry-level Graduate Engineer Trainees, following are the keyaspects of training

$>$ Personality Development.

> Communication Skills \& Vocabulary.

$>$ Resume Preparation \& Email Writing.

$>$ Group Discussion.

$>$ Interview Skills.

> Aptitude Training \& Practice Tests.

Foreign Languages such as Japanese \& German.

In this application we are using natural language processing to create a chatbot to navigate through all the modules of the system, carrying out tests and skill development activites to moniter student improvement and skills. This application also provides various recommandation based on user need and keep notified about all the training and placement related news and information.

\section{PROBLEM STATEMENT}

While conducting interview the company may need list of recommanded candidates fit for the job criteria, it has to manually go through the records of all the student and has to depend on their resume for judging their skills, the students seeking or preparing for the job need proper guidance to prepare themselves for the interview to attain industry level skill set they need to go through proper training and analysis which is either slow or inefficient in traditional training and placement procedure.

\subsection{Motivation}

Our analysis points out the high number of papers related to various application of chatbot in the field of 
management. There is no implementation of such technology in training and placement.

Our motive is to create fully automated solution to the training and placement process where both the student and the training and placement coordinator can utilise our Platform to play their individual respective role more effeciently, being a candidate seeking for jobs one must be notified with news about various job openenings and campus drives due to absence of a unified personal communication platform admin may not able to reach each and every candidate ,a $24 \times 7$ solution to the guidance and communication is provided in our proposed system

\subsection{LITERATURE REVIEW}

This section explores literature review. For more details, see table 1

\section{> Chatbot for University Related FAQs(2017)}

Articial Intelligence Markup Language (AIML) and Latent Semantic Analysis (LSA) are used for developing chatbots, which are used to dene general queries like how do you do?, how can I help you etc. This pattern can also be used to give random responses for same query. LSA is a Latent Semantic Analysis, which is utilized to discover likenesses between words as vector representation. So that the unanswered queries by AIML will be viewed as a reply by LSA. Most chatbots basically search for keywords, phrases, and examples that have been customized into their databases, yet some utilize more propelled strategies. So far no chatbot has possessed the capacity to totally trick people into trusting it as one of them through its information of regular dialect. In this paper the need for chatbot in education domain is highlighted and designed to provide visitor satisfaction.

AIML is Articial Intelligence Markup Language (AIML) and Latent Semantic Analysis (LSA) are used for developing chatbots, which are used to dene general queries like how do you do?, how can I help you etc. This pattern can also be used to give random responses for same query. LSA is a Latent Semantic Analysis, which is utilized to discover likenesses between words as vector representation. So that the unanswered queries by AIML will be viewed as a reply by LSA. Most chatbots basically search for keywords, phrases, and examples that have been customized into their databases, yet some utilize more propelled strategies. So far no chatbot has possessed the capacity to totally trick people into trusting it as one of them through its information of regular dialect. In this paper the need for chatbot in education domain is highlighted and designed to provide visitor satisfaction. Uses the Artificial Intelligence Markup Language (AIML) to simulate human FAQs releted to University

\section{Developing a Chatbot For College Student Programme Advertisement(2018)}

Academic advisement has been widely regarded as an essential student support service in higher education. Student advisement typical refers to services supporting course selection, general mentorship, and career planning. Giving college students timely and relevant advice is known to positively influence student retention, progression, and graduation. Academic advisement provides many institutional benefits, including increased student loyalty and prospective student recruitment.

\section{A Noval Approach For Medical Assistance Using Trained Chatbot(2017)}

The proposed idea is to create a system with artificial intelligence that can meet the requirements. The AI can predict the diseases based on the symptoms and give the list of available treatments. The System can also give the composition of the medicines and their prescribed uses. It helps them to take the correct treatment. Hence the people can have an idea about their health and can have the right protection

\section{Home Automation using IoT and a Chatbot using Natural Language Processing}

Home automation - controlling the fans, lights and other electrical appliances in a house using Internet of things is widely preferred in recent days. In this paper, we propose a web application using which the fans, lights and other electrical appliances can be controlled over the Internet. The important features of the web application is that firstly, we have a chatbot algorithm such that the user can text information to control the functioning of the electrical appliances at home. The messages sent using the chatbot is processed using Natural Language processing techniques. Secondly, any device connected to the local area network of the house can control the devices and other appliances in the house. Thirdly, the web application used to enable home automation also has a security feature that only enables certain users to access the application. And finally, it also has a functionality of sending an email alert when intruder is detected using motion sensors. 
$>$ Programming challenges of Chatbot: Current and Future Prospective(2017)

chatbot is an instant messaging account that able to provide services using instant messaging frameworks with the aim of providing conversational services to users in an efficient manner. A chatbot is fast with less confusing web and mobile application which is easy to install as there is no need to have installation packages. These packages are easy to manage and distribute. Chatbots are totally different from the human accounts as they do not have any online status or last seen timestamps nor initiate the conversations and calls with any other accounts.Intent classification module identifies the intent of user message. Entity recognition module extracts structured bits of information from the message. The candidate response generator is doing all the domain-specific calculations to process the user request. The response selector just scores all the response candidate and selects a response which should work better for the user.

Table 1: comparison between reference papers

\begin{tabular}{|c|c|c|c|c|}
\hline Sr.No. & Year & System & Advantages & tions \\
\hline 1 & 2017 & $\begin{array}{l}\text { Chatbot for University } \\
\text { Related FAQs }\end{array}$ & $\begin{array}{l}\text { It provide full informations } \\
\text { about frequently asked } \\
\text { questions related to students } \\
\text { queries. }\end{array}$ & $\begin{array}{lrr}\text { It doesnt } & \text { provide } & \text { navigation } \\
\text { throughout } & \text { various } & \text { website } \\
\text { operations } & & \end{array}$ \\
\hline 2 & 2018 & $\begin{array}{lr}\text { Developing a Chatbot for } \\
\text { College } & \text { Student } \\
\text { Programme } & \\
\text { Advisement } & \end{array}$ & $\begin{array}{l}\text { It provides information about } \\
\text { student } \\
\text { advertisement. }\end{array}$ & $\begin{array}{l}\text { It is not applicable for interaction } \\
\text { with various other operations } \\
\text { other than student programme } \\
\text { advertisement. }\end{array}$ \\
\hline 3 & 2017 & $\begin{array}{l}\text { A Novel Approach for } \\
\text { Medical Assistance } \\
\text { Using Trained Chatbot }\end{array}$ & $\begin{array}{l}\text { It provide assistance to } \\
\text { patients } 0 \text { through human } \\
\text { computer interaction. }\end{array}$ & $\begin{array}{l}\text { It is only } \\
\text { assistance. }\end{array}$ \\
\hline 4 & 2017 & $\begin{array}{l}\text { Home Automation using } \\
\text { IoT and a Chatbot using } \\
\text { Natural Language } \\
\text { Processing. }\end{array}$ & $\begin{array}{l}\text { It provides full control over } \\
\text { home automation through AI } \\
\text { based chatbot. Inent? }\end{array}$ & $\begin{array}{l}\text { It's functionality is only limited } \\
\text { in home automations operations. }\end{array}$ \\
\hline
\end{tabular}

\section{PROPOSED SYSTEM}

The Proposed System application is developed as a tool to implement automated solution to the training and placement management procedure by providing artificial intelligence based approach, we provide with a system where human computer interaction takes place which provide smart solution to the existing system which is traditionally carried out with a manual approach, This system also consist of various modules and additional features which generate more efficient and sophisticated outcome from the system ,by adding various Artificial Intillegence based system components such as chatbot for interaction with the System and navigating through the modules, recommendation system to provide efficient recommended outcome based on various conditions taking into consideration user's motive and needs, the System architecture is fully described below in the Fig. 1: System Architecture, following are the objective of the proposed system ;

This system provide full solution to the manually done procedure of Training and Placement.

$>$ A chatbot to provide full assistance and navigate through all the modules of the system.

$>$ Improvises and moniter student skill set by taking various computer based exams.

provide recommanded candidate's list according to their skillset.

$>$ Display various news and relevant information. 


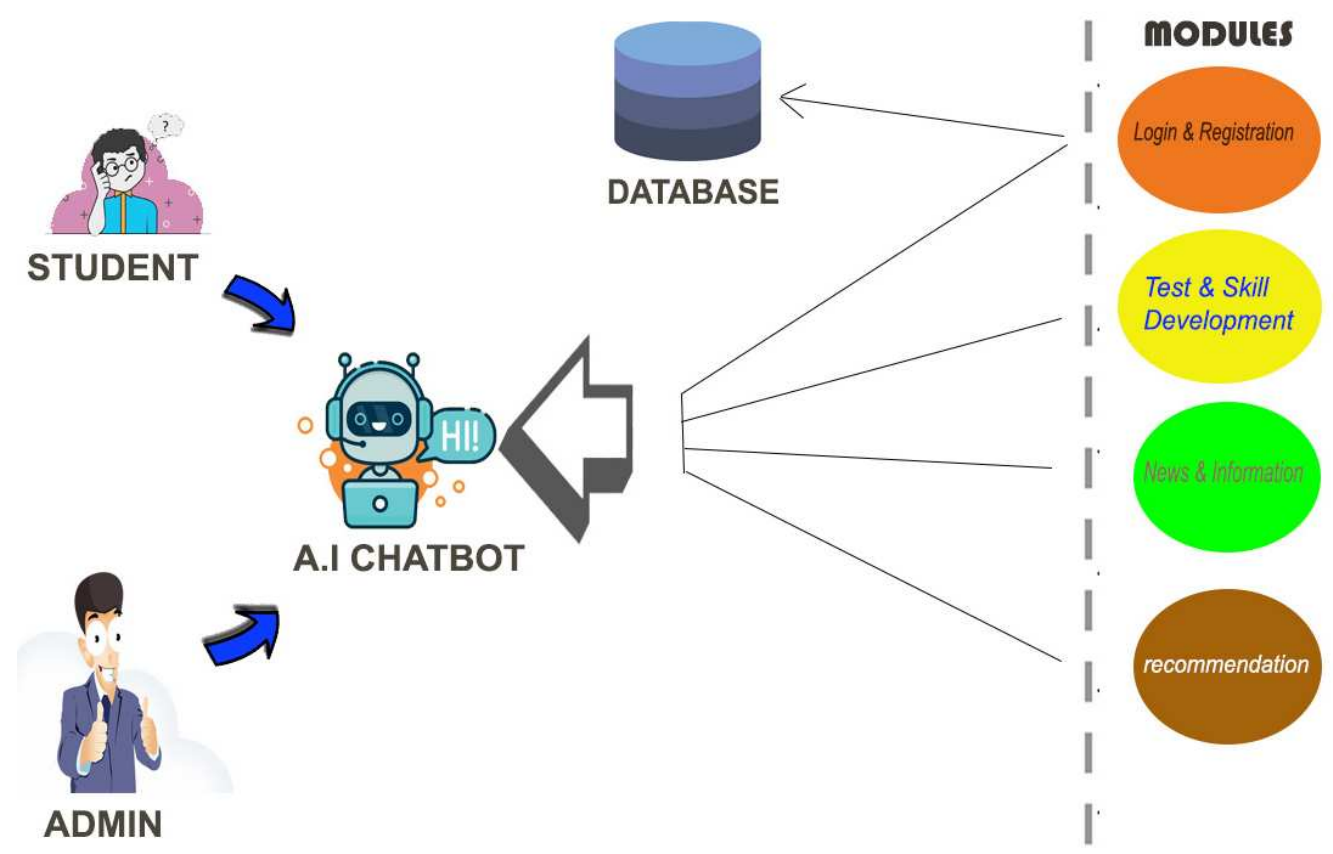

Fig. 1: System details of Admin and Student carrying out Training and Placement procedure through proposed system (System Architecture)

\section{REFERENCES}

1. Ranoliya, Bhavika $\mathrm{R}$ and Raghuwanshi, Nidhi and Singh, Sanjay, Chatbot for university related FAQ's, in Advances in Computing, Communications and Informatics (ICACCI), 2017 , pp. 15251530.

2. Rahman, AM and $\mathrm{Al}$ Mamun, Abdullah and Islam, Alma, Programming challenges of chatbot: Current and future prospective, Humanitarian Technology Conference (R10-HTC), 2017 IEEE Region 10, pp. 75-78.

3. Albayrak, Naz and Ozdemir,"Aydeniz and Zeydan, Engin, An overview of artificial intelligence based chatbots and an example chatbot application, Signal Processing and Communications Applications Conference (SIU), 2018, pp. 1-4.

4. Hussain, Shafquat and Athula, Ginige, Extending a conventional chatbot knowledge base to external knowledge source and introducing user based sessions for diabetes education, in Advanced Information Networking and Applications Workshops (WAINA), 2018, pp. 698-703.

5. Baby, Cyril Joe and Khan, Faizan Ayyub and Swathi, JN, Home automation using IoT and a chatbot using natural language processing, in Power and Advanced Computing Technologies (iPACT), 2017 Innovations, 2017, pp. 1-6.
6. Choi, Hanjong and Hamanaka, Takeshi and Matsui, Kanae, Design and implementation of interactive product manual system using chatbot and sensed data, in Consumer Electronics (GCCE), 2017 IEEE 6th Global Conference, 2017, pp. $1-7$.

7. D'silva, Godson Michael and Thakare, Sanket and More, Sharddha and Kuriakose, Jeril, Real world smart Chatbot for customer care using a software as a service (SaaS) architecture, in I-SMAC (IoT in Social, Mobile, Analytics and Cloud)(ISMAC), 2017 International Conference, 2017,pp. 658-664

8. Yushendri, Jefri and Hanif, Alvian Rahman and Siswadi, AnnekeAnnassia Putri and Musa, Purnawarman and Kusuma, Tubagus Maulana and Wibowo, Eri Prasetyo, A speech intelligence conversation bot for interactive media information, in Informatics and Computing (ICIC), 2017 Second International Conference, 2017, pp. 1-6.

9. Setiaji, Bayu and Wibowo, Ferry Wahyu, Chatbot using a knowledge in database, in 7th International Conference on Intelligent Systems, Modelling and Simulation, 2017 